\title{
Formação de professores: um esforço de síntese ${ }^{*}$
}

\section{Formation of professors: a synthesis effort}

\author{
Ione Ribeiro Valle**
}

\begin{abstract}
RESUMO
Este estudo analisa a produção acadêmica de dois grupos de trabalho: Formação de Professores e Sociologia da Educação, a partir de estudos apresentados nas Reuniões Anuais da Anped e no Seminário da Região Sul (1998). Nosso objetivo consiste em investigar o interesse que os temas formação de professores e profissionalização do corpo docente têm despertado entre os sociólogos da educação, assim como a influência de sociólogos estrangeiros na produção socioeducacional brasileira. Para tanto, foram repertoriados minuciosamente todos os trabalhos e comunicações apresentadas entre 1995 e 2000, classificando-os por tema central; em seguida, procedemos à seleção de alguns trabalhos, que mereceram uma análise mais aprofundada. Finalmente, elaboramos uma síntese apoiada nas conclusões dos estudos selecionados, privilegiando três aspectos básicos, a saber: um novo perfil de professor, a profissionalização e a formação de professores, visando construir categorias de análise que poderão orientar outras pesquisas em curso nessa área de conhecimento. Palavras-chave: formação de professores, profissionalização, corpo docente, sínteses.
\end{abstract}

* Uma primeira versão deste estudo foi apresentada no IV Seminário de Pesquisa em Educação da Região Sul - Anped, realizado em Florianópolis, de 26 a 29 de novembro de 2002.

${ }^{* *}$ Doutora em Ciências da Educação (Faculdade de Ciências Humanas e Sociais - Sorbonne Universidade René Descartes - Paris V). Professora do Centro de Ciências da Educação da Universidade Federal de Santa Catarina - UFSC. E-mail: ionvalle@newsite.com.br 


\begin{abstract}
This study analyzes the academic production of two work groups: Formation of Professors and Sociology of the Education, coming from the studies presented in Anped (the Brazilian National Association on Research and Graduate Studies in Education) Annual Meetings and the Anped's Seminary of the South Region (1998). Our objective consists on investigating the interest that the subjects such as formation of professors and professionalization of the faculty have awakened among the sociologists of the education, as well as the influence of foreign sociologists in the Brazilian socio-educational production. For in such a way, the works and communications presented between 1995 and 2000 had been collected all minutely and classified by their central subject; after that, we proceeded the election from some works, that had deserved a more deepened analysis. Finally, we have elaborated a synthesis supported in the conclusions of the selected studies, privileging three basic aspects, to know: a new profile of professor, the professionalization and the formation of professors, aiming to construct some categories of analysis that will be able to guide more research in course in this area of knowledge.

Key-words: formation of professors, professionalization, faculty, syntheses.
\end{abstract}

Uma das maiores dificuldades a serem enfrentadas pelo sociólogo ao longo de seu percurso consiste em assegurar-se da pertinência de sua escolha teórico-metodológica. Esta dificuldade está relacionada à complexidade do assunto estudado, que geralmente envolve diferenciados campos de investigação científica. Se o fato de colocar corretamente o problema da pesquisa facilita a seleção e a utilização dos instrumentos de análise, é o exame rigoroso dos trabalhos realizados em torno do tema que conduzirá à elucidação de novos elementos, à clareza teórica, indispensáveis à interpretação das questões/hipóteses levantadas, e à análise/compreensão das respostas obtidas.

Segundo Bachelard (1965), a "experiência científica" do campo de investigação se reflete sobre o olhar que o sociólogo dirige, desde o início, ao assunto escolhido. Confrontando-se com uma quantidade enorme de informações que se cruzam, se recortam e se entrelaçam, o pesquisador modifica consideravelmente esse olhar a partir do que observa durante o trabalho de campo. Assim, para dominar melhor seu assunto, deve munir-se não somente de estudos já concluídos, mas também - e talvez principalmente - de trabalhos em andamento. A fim de traçar a evolução científica de seu tema e destacar os aspectos que mais merecem sua atenção, o sociólogo deve repertoriá- 
los e examiná-los minuciosamente, visando clarear o caminho a perseguir e facilitar o alcance de seus objetivos.

Nesta perspectiva, dedicamo-nos à elaboração de uma síntese que orientou nossa trajetória de pesquisadores e que contribuiu para a elucidação do tema em questão e construção de categorias de análise. Para elaborar esta síntese, inspiramo-nos na reflexão formulada por Forquin (1996) sobre a importância do trabalho de síntese na pesquisa educacional. Segundo ele, "pelas aproximações que opera, as separações ou as defasagens que sugere, as redundâncias que acentua, as lacunas que descobre, a síntese permite a reflexão e desenha, em filigrana, programas e perspectivas de pensamento". A síntese implica em um trabalho de seleção e de estruturação, que não significa justapor as informações, nem adicioná-las mecanicamente, mas configurá-las, organizá-las, recompô-las:

o autor de uma síntese tem um dever de imparcialidade, a obrigação de explicar o campo que descreve de modo objetivo e equilibrado. Porém, nenhuma colocação em perspectiva é totalmente neutra: o fato de apresentar as coisas em tal ou qual ordem, em função de tal ou qual progressão, de operar esta ou aquela aproximação, acentuar este ou aquele contraste, sugerir uma ou outra filiação, ou tal ou qual ruptura tem sempre, senão um valor polêmico, ao menos um valor de avaliação, um valor crítico. (FORQUIN, 1996).

\section{O caminho escolhido}

Apesar de haver uma insuficiência de estudos sociológicos no campo educacional brasileiro, não podemos pretender estudá-los todos aqui. Uma grande parte desses estudos ainda não está publicada, eles estão sendo desenvolvidos em diferentes instituições, tratam de temas diversos com base em abordagens distintas, fatores que tornam difícil sua identificação. Ainda, a elaboração de sínteses, consideradas como necessárias à sistematização do processo de produção de conhecimentos, está apenas iniciando-se no Brasil. Foi preciso, então, procurar um caminho que permitisse ao mesmo tempo recolher metodicamente os trabalhos e construir um corpus que representasse a formação de professores no âmbito nacional. Como salientou Forquin (1996), 
“o corpus sobre o qual deve se efetuar o trabalho de síntese não se constrói 'a priori', mas sim graças às leituras e às chamadas de referência de um texto a outro, por ampliações ou enriquecimentos sucessivos".

Visando conhecer as prioridades dos pesquisadores brasileiros e apreender a emergência de novos temas, assim como o desaparecimento de outros, examinamos alguns trabalhos apresentados em reuniões anuais da Associação Nacional de Pós-Graduação e Pesquisa em Educação (Anped). Por sua produção e divulgação de estudos sobre a educação, por sua mobilização em todas as regiões do país, esta associação conquistou o reconhecimento do meio acadêmico e goza de legitimidade junto aos sistemas de ensino e às esferas representativas do pessoal da educação.

A Anped (criada em 1976) é o resultado da "obstinação" dos programas de Pós-Graduação em educação (ligados às universidades) no que concerne a socialização dos trabalhos de pesquisa: seu objetivo é produzir uma base de conhecimentos sobre os sistemas de ensino, considerada até então insuficiente. A Anped se emancipa em 1979 da tutela das universidades e engaja-se ativamente na construção de novas referências teóricas e críticas para a educação nacional, em parceria com outras associações representativas do magistério. Segundo Daros (1994), estas associações tinham como meta primordial a unificação das lutas dos professores em torno da democratização da educação, e acabaram colocando em cena novos atores sociais, que exercem forte pressão sobre o Estado, conduzindo-o a integrar demandas socioeducacionais anteriormente ignoradas pelas políticas e práticas oficiais.

A Anped aparece como um importante fórum de discussão das questões científicas e políticas relativas à educação nacional. Seus objetivos consistem em motivar a produção de pesquisas e divulgar os conhecimentos adquiridos durante as reuniões anuais. ${ }^{1}$ Esta Associação é organizada em Grupos de Trabalho (GTs), distribuídos nos seguintes temas: história da educação, movimentos sociais e educação, didáticas, Estado e política, educação popular, educação das crianças de zero a seis anos, formação dos professores, trabalho e educação, alfabetização, leitura e escrita, política da educação superior, currículo, educação fundamental, sociologia da educação, educação especial, educação e comunicação, filosofia da educação, psicologia da educação, educação matemática, educação do pessoal jovem e adulto. ${ }^{2}$ Estes grupos selecionam, entre numerosas proposições, os trabalhos que integram a agenda anual da Anped.

\footnotetext{
${ }^{1}$ Cf. Guia da Anped, publicado em 1999.

${ }^{2}$ Grupos de Trabalho em funcionamento (2001).
} 


\section{A seleção de trabalhos}

Para elaborar esta síntese, analisamos o conjunto de trabalhos ${ }^{3}$ apresentados nas reuniões anuais (realizadas entre 1995 e 2000) e no Seminário da Região Sul (que aconteceu em 1998), classificados nos seguintes grupos: GT Formação dos professores (que trata diretamente do assunto em foco) e GT Sociologia da educação (que constitui sua principal base epistemológica). A partir da leitura dos resumos (ou das introduções e, muitas vezes, das conclusões), fizemos uma primeira triagem visando identificar os trabalhos sobre a formação e a profissionalização do corpo docente, respeitando os princípios da heurística sociológica que colocam em evidência "a crítica reflexiva, como atividade intelectual necessária ao movimento e à renovação da pesquisa e de sua progressão" (ANSART, 1999).

\section{Os trabalhos repertoriados}

Lembremos que o Brasil ainda dispõe de poucas pesquisas em ciências humanas e sociais, porém progressos consideráveis foram realizados nessas áreas, como comprova a quantidade de trabalhos apresentados nas reuniões anuais: foram repertoriados 156 trabalhos (entre 1995 e 2000). Observamos o que parece evidente - que a maioria dos trabalhos (58\%) que tratam da formação e da profissionalização deriva do GT Formação dos professores (quadro 1), o que explica a seleção quantitativa efetuada. Esses temas só aparecem entre os trabalhos do GT Sociologia da educação em 1998. ${ }^{4}$ Selecionamos também 29 trabalhos do GT Formação dos professores, apresentados no Seminário de Pesquisa em Educação da Região Sul. ${ }^{5}$

3 Os estudos dos anos 1995 e 1996 foram classificados como "trabalho" ou como "comunicação". Os trabalhos pressupunham uma densidade maior do que as comunicações. Depois de 1997, todos foram classificados como "trabalho".

4 Sobre a sociologia na formação dos professores do Estado de Santa Catarina, ver: Daros, Nascimento e Daniel (2000), Tornquist e Valle (1995, p. 11-20).

5 Reunidos durante a 20a Reunião Anual da Anped (em 1997), os coordenadores dos Programas de Pós-Graduação da Região Sul declararam sua preocupação com relação à divulgação dos trabalhos de pesquisa ali produzidos. Tendo o apoio da Anped, estes coordenadores realizaram o Seminário de Pesquisa em Educação (em julho de 1998, na Universidade Federal de Santa Catarina). Esse seminário teve por objetivo relacionar, divulgar e valorizar a produção regional: 307 trabalhos foram inscritos ( $62 \%$ decorrentes de teses de doutorado e de dissertações de mestrado). Estes trabalhos foram divididos em 15 temas, dos quais selecionamos treze referentes à formação de professores. 
No que se refere à escolha metodológica, pudemos verificar que as análises qualitativas predominam, enquanto que as análises quantitativas ou as que conjugam dados numéricos e dados qualitativos são raras. Os fundamentos teóricos levantados mostram empréstimos estrangeiros, notadamente francófonos ou anglófonos, traduzidos em português ou em espanhol. O recurso à sociologia da educação francesa, clássica ou contemporânea, é muito freqüente.

QUADRO 1 - TRABALHOS REPERTORIADOS E SELECIONADOS, SEGUNDO O GRUPO DE TRABALHO. REUNIÕES ANUAIS DA ANPED (1995 A 2000*) E SEMINÁRIO DA REGIÃO SUL $(1998 * *)$

\begin{tabular}{|c|c|c|c|c|c|c|c|c|c|c|c|c|c|c|}
\hline \multirow{3}{*}{$\begin{array}{l}\text { Grupos de } \\
\text { Trabalho }\end{array}$} & \multirow{2}{*}{\multicolumn{2}{|c|}{ Total }} & \multicolumn{12}{|c|}{$\begin{array}{c}\text { Reuniões Anuais e Seminário da Região Sul }\left(\mathrm{n}^{\circ} \mathrm{de}\right. \\
\text { trabalhos) }\end{array}$} \\
\hline & & & \multicolumn{2}{|c|}{1995} & \multicolumn{2}{|c|}{1996} & \multicolumn{2}{|c|}{1997} & \multicolumn{2}{|c|}{1998} & \multicolumn{2}{|c|}{1999} & \multicolumn{2}{|c|}{2000} \\
\hline & $\mathrm{R}$ & S & $\mathrm{R}$ & $\mathrm{S}$ & $\mathrm{R}$ & S & $\mathrm{R}$ & S & $\mathrm{R}$ & S & $\mathrm{R}$ & S & $\mathrm{R}$ & S \\
\hline $\begin{array}{l}\text { Formação de } \\
\text { Professores* }\end{array}$ & 90 & 42 & 14 & 7 & 12 & 6 & 10 & 5 & 16 & 9 & 19 & 8 & 19 & 7 \\
\hline $\begin{array}{l}\text { Sociologia da } \\
\text { Educação* }\end{array}$ & 66 & 6 & 12 & & 8 & & 6 & & 14 & 1 & 13 & 2 & 13 & 3 \\
\hline $\begin{array}{l}\text { Formação de } \\
\text { Professores } * *\end{array}$ & 29 & 13 & & & & & & & 29 & 13 & & & & \\
\hline Total & 185 & 61 & 26 & 7 & 20 & 6 & 16 & 5 & 59 & 23 & 32 & 10 & 32 & 10 \\
\hline
\end{tabular}

LEGENDA: $\mathrm{R}=$ TRABALHOS REPERTORIADOS; $\mathrm{S}$ = TRABALHOS SELECIONADOS.

Em sua maioria, os trabalhos são construídos a partir de uma diversidade de abordagens teórico-metodológicas (psicológica, filosófica, didática, pedagógica, sociológica, histórica, etc.). Os pesquisadores - a maioria deles debutantes - se apoiaram em diferentes bases epistemológicas com o objetivo de tornar mais clara sua problemática. Este procedimento lhes pareceu muito enriquecedor do ponto de vista intelectual, por permitir fundamentar e redimensionar suas pesquisas. Do ponto de vista pessoal, essa diversidade epistemológica abriu novos horizontes no campo da pesquisa interdisciplinar.

Examinemos em seguida os temas sobre os quais se basearam os trabalhos dos GTs Formação dos professores e Sociologia da educação (quadro 2).

1. Os temas do GT Formação de professores compreendem: a) a relação entre a universidade e a Educação Básica, tema construído com base nos estudos sobre as experiências de reorganização das habilitações de formação inicial e nos programas destinados à formação contínua dos professores; b) a 
política nacional de educação, tema que agrupa as análises dos dispositivos legais aplicados pelo governo, seu impacto sobre os sistemas de ensino, bem como aquelas que tratam das revisões do currículo; c) a prática pedagógica, tema que reúne as experiências inovadoras de avaliação da aprendizagem e preconiza a produção de conhecimentos a partir da reflexão crítica da prática; d) a profissionalização do corpo docente, tema que levanta as trajetórias pessoais e profissionais que influenciam e mesmo determinam o engajamento na carreira docente; e) a formação dos professores. Tema que reúne trabalhos de avaliação da formação para as diversas disciplinas curriculares, desenvolvidas principalmente nos programas de formação; f) as sínteses que examinam a produção científica sobre o tema formação dos professores. ${ }^{6}$

2. Os temas apresentados no GT Sociologia da educação abrangem: a) os aspectos sociohistóricos da educação, tema que privilegia o percurso de certas instituições de ensino, assim como a contribuição de certos autores; b) as relações de poder, tema que trata do exercício da autoridade nos sistemas de ensino e seus impactos sobre a carreira do professor, a prática pedagógica; c) a educação, cultura e mudança social, temas que enfocam a situação de crise na educação, as perspectivas da modernidade e os novos desafios impostos à escola, bem como o estudo de trajetórias escolares bem sucedidas; d) a educação das minorias, tema que abrange sobretudo a análise de processos de escolarização de comunidades indígenas; e) a formação dos professores, tema que reúne os estudos sobre a escolaridade inicial e as experiências de formação contínua; f) as sínteses dos trabalhos de alguns sociólogos da educação ${ }^{7}$ e de algumas abordagens teóricas.

6 Interessando-se pela situação da pesquisa realizada junto à formação dos professores no Brasil, André (1998) analisou as teses de doutorado e as dissertações de mestrado defendidas entre 1990 e 1995 (236 trabalhos). O autor constatou que mais da metade desses trabalhos estudaram a Escola Normal, os cursos de pedagogia ou a formação contínua; 14\% se detiveram na formação dos professores da Região Sul, somente $0,4 \%$ enfocaram a problemática no Estado de Santa Catarina.

7 Interessado na trajetória da sociologia da educação nos cursos de mestrado das universidades do Nordeste do Brasil, Ferreira (1999) examina as dissertações defendidas entre 1988 e 1997 (244 trabalhos). O autor verifica que esta disciplina desempenhou um papel muito importante na socialização do campo educativo brasileiro: apesar do modelo educativo em vigor permanecer muito identificado com a ideologia dos anos 70, quando predominavam o interesse pelo planejamento e pela tecnologia educativa, a opção teórica da sociologia da educação está, desde os anos 80, baseada em abordagens marxistas que atribuem à escola um papel central na reprodução das classes sociais. Ela aparece agora como fundamental à formação da consciência crítica, indispensável à transformação da sociedade. 
QUADRO 2 - TEMAS DAS REUNIÕES ANUAIS DA ANPED (1995 A 2000) E DO SEMINÁRIO DA REGIÃO SUL (1998*), SEGUNDO OS TRABALHOS REPERTORIADOS NOS GRUPOS DE TRABALHO

\begin{tabular}{|c|c|c|c|c|c|c|c|}
\hline \multirow{2}{*}{$\begin{array}{c}\text { Grupos } \\
\text { de } \\
\text { Trabalho }\end{array}$} & \multirow{2}{*}{ Temas } & \multicolumn{6}{|c|}{ Reuniões Anuais ( $\mathrm{n}^{\circ}$ de trabalhos) } \\
\hline & & 1995 & 1996 & 1997 & $1998^{*}$ & 1999 & 2000 \\
\hline \multirow{6}{*}{ 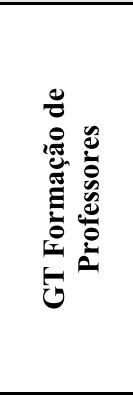 } & $\begin{array}{l}\text { Universidade e Educação } \\
\text { Básica }\end{array}$ & 4 & 4 & 4 & 9 & 2 & 1 \\
\hline & $\begin{array}{c}\text { Política Nacinal de } \\
\text { Educação }\end{array}$ & 2 & 2 & & 7 & 2 & 1 \\
\hline & Prática Pedagógica & 3 & 1 & 4 & 8 & 4 & 7 \\
\hline & $\begin{array}{c}\text { Profissionalização do Corpo } \\
\text { Docente }\end{array}$ & 1 & 3 & 1 & 2 & 3 & \\
\hline & Formação de Professores & 3 & 2 & 1 & 18 & 7 & 10 \\
\hline & Sínteses & 1 & & & 1 & 1 & \\
\hline \multirow{6}{*}{ 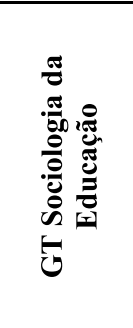 } & $\begin{array}{c}\text { Aspectos Sociohistóricos } \\
\text { da Educação }\end{array}$ & 2 & 2 & 1 & 1 & 1 & \\
\hline & Poder e Educação & 7 & 2 & 2 & 5 & 3 & 1 \\
\hline & $\begin{array}{c}\text { Educação, Cultura e } \\
\text { Mudança Social }\end{array}$ & 2 & 3 & 2 & 4 & 7 & 8 \\
\hline & Educação das Minorias & & & & 2 & & 1 \\
\hline & Formação de professores & & & & 1 & 1 & 2 \\
\hline & Sínteses & 1 & 1 & 1 & 1 & 1 & 1 \\
\hline \multicolumn{2}{|r|}{ Total } & 26 & 20 & 16 & 59 & 32 & 32 \\
\hline
\end{tabular}

\section{A síntese}

Para elaborar esta síntese, selecionamos 61 trabalhos, apresentados sob a forma de artigos (33\% do total levantado, sendo que $90 \%$ deles pertencem ao GT Formação de Professores). Eles foram agrupados em três linhas temáticas, a saber: um novo perfil do professor, a profissionalização e a formação. Ainda que essas linhas repousem sobre fundamentos teórico-metodológicos similares, elas apresentam uma certa especificidade, permitindo distingui-las. Os estudos teóricos e microsociológicos são predominantes. Os últimos se apóiam geralmente em métodos autobiográficos e examinam experiências pontuais. Os trabalhos reunidos na primeira linha visam mais conceituar do que estudar situações concretas; os da segunda e da terceira linhas buscam as noções teóricas que podem explicar as microrealidades observadas. 
Observemos que os trabalhos selecionados estão marcados por uma certa ambivalência. Se, por um lado, se mostram relativamente pessimistas em relação à educação nacional, por outro, revelam-se muito otimistas no que concerne ao papel da prática docente na transformação social. A maioria deles critica as políticas econômicas, orientadas conforme o modelo neoliberal, que visa reforçar as desigualdades de classe e reproduzir as relações de dominação entre capital e trabalho, impedindo a democratização da educação. Existe, entretanto, uma forte tendência a acreditar que os professores são capazes de combater os efeitos perversos dessas políticas pela adoção de uma prática pedagógica competente, calcada em novos parâmetros.

Os pesquisadores são unânimes ao mencionarem a ausência de estudos que permitam conhecer melhor os problemas educacionais do país, colocando em dúvida os compromissos sociais assumidos historicamente pela universidade brasileira. Tomemos como exemplo as considerações de Linhares (1995): embora a profissão de professor esteja entre as ocupações que aumentam consideravelmente no Brasil, ela quase não suscitou o interesse dos sociólogos da educação, nem o dos sociólogos do trabalho. Segundo ele, há uma distância importante entre o "discurso elitista da universidade" e as verdadeiras necessidades da escola pública, fenômeno revelador do fraco engajamento do mundo acadêmico na Educação Básica.

\section{Um novo perfil de professor}

A construção de um novo modelo educacional supõe um novo perfil docente. O professor missionário não satisfaz mais. Tornou-se necessário preparar um professor profissional, que não se limite a transmitir os conhecimentos, mas que também os produza. ${ }^{8}$ Os trabalhos examinados aqui preconizam dois aspectos: uns estão relacionados à função docente, outros valorizam a experiência adquirida na prática.

Esses trabalhos referem-se ao professor como ator, agente ou sujeito (termos empregados de modo equivalente). Em todos os sentidos, ele aparece no centro das expectativas de transformação social. É, de preferência, o ensino público, em todos os seus níveis, que interessa a esses pesquisadores. Eles sonham em sacudir a atual dinâmica dos sistemas de ensino e colocar a escola pública a serviço das mudanças desejadas.

8 Alguns trabalhos rediscutem as abordagens teóricas sobre o fracasso escolar (CORD, 1998) e o conceito de cultura (ENGERS, 1998). Outros enfatizam a relação entre educação e estratificação social (ALMEIDA, 2000). Outros ainda analisam a identidade profissional de professores primários (VILELA, 2000). 
A maioria dos trabalhos insiste na dicotomia entre teoria e prática, alimentada pelas diferentes modalidades de socialização profissional. É sobre a bagagem teórica, adquirida durante a formação inicial, que se fundamenta a noção de competência. Ora, valorizando a aquisição teórica, há um desprezo pela experiência obtida na prática, fruto dos anos de trabalho.

Certos artigos apresentam uma concepção fortemente evolucionista da função docente, colocando-a entre dois pólos opostos: professor passivo $\mathrm{x}$ professor reflexivo, professor objeto x professor sujeito, professor diplomado x professor não-diplomado, professor competente x professor incompetente. A passagem de um pólo ao outro depende da reestruturação dos sistemas de ensino e da melhoria das condições de trabalho, ou do engajamento do próprio professor em sua carreira profissional. Essa passagem é posta sempre em perspectiva quando os autores se referem às mudanças educacionais.

Tornar-se professor pesquisador ou professor reflexivo (expressões usadas como sinônimos) significa aproveitar a experiência cotidiana para transformar a prática pedagógica em fonte de conhecimentos. Para Carvalho e Simões (1996), é preciso preparar os professores para extraírem da prática pedagógica tanto os aspectos que merecem críticas, quanto os que favorecem a auto-avaliação. Spilimberg e Oliveira (1998) observam que a experiência da classe deve ser utilizada como referência na formação contínua. Estes últimos julgam que a formação inicial está muito distanciada da prática de ensino, e que ela não está à altura de preparar o professor para o exercício competente da profissão.

Dickel (1997) considera que a produção de conhecimentos deve resultar de um trabalho coletivo, que trate da realidade na qual se desenvolve a atividade de ensino: para dar sustentação aos professores inovadores, é preciso que a pesquisa faça parte do projeto pedagógico da escola. $\mathrm{O}$ caminho dos professores é quotidianamente atravessado pela imposição de modelos educativos que não se adaptam às condições concretas da escola, assinala o autor. Em um outro trabalho apresentado em 1998, Dickel observa que os professores não podem mais ser sujeitos passivos, limitando-se a transmitir conhecimentos concebidos fora da prática escolar: esses sujeitos produzem uma riqueza de conhecimentos que devem ser aproveitados pelos programas de formação, no sentido de orientar as mudanças que se deseja operar no interior da escola.

Brunstein et al. (1995) consideram que a insatisfação dos professores e sua vontade de inovar não são suficientes para provocar mudanças. Para evitar ajustar-se ou dar prova de conivência às pressões impostas pela administração dos sistemas de ensino, os professores devem partilhar as experiências 
bem-sucedidas e as soluções encontradas diante das dificuldades dos alunos: os professores devem adquirir o hábito de se ajudarem mutuamente.

Para Zasso (1998), o professor torna-se muito mais aberto às mudanças pedagógicas avaliando sua prática e dela produzindo suas próprias respostas. Segundo Grillo et al. (1998), é preciso aproveitar a oportunidade da formação para encorajar a reflexão coletiva, o que deve partir das questões colocadas pelos professores e de suas motivações em relação às inovações. Esses pesquisadores insistem na experiência adquirida nas diferentes fases da vida profissional, assinalando que é preciso desmistificar a falsa noção de que a eficiência da prática de ensino depende exclusivamente da formação inicial.

Igualmente, Roseli Rodrigues de Mello (1998) refere-se à riqueza da experiência pessoal, sublinhando que ela deve ser objeto de estudo e fator de referência por ocasião da elaboração dos programas de formação. Bueno (1997) entende que a prática de ensino é o espaço privilegiado de produção de conhecimentos, indispensáveis ao desenvolvimento do pensamento, devendo fundamentar as políticas de formação dos professores. Analisando a reforma educacional na Argentina, Bergin (1998) observa que um novo Estado está em construção, definindo um novo lugar para o público e para o privado. É um processo de reconstrução da carreira docente que engendra uma nova escola, assim como um novo perfil de professor e novas formas de escolarização.

Após analisar algumas abordagens teóricas, Nuñez e Ramalho (1997) preconizam a elaboração de um "modelo profissional" baseado em um novo perfil de professor. Esse modelo deve apoiar-se na experiência, tida como a única maneira de atenuar o descompasso entre o que prescreve o currículo e o que se ocorre na relação pedagógica. Até então, acentuam eles, as políticas de formação não valorizaram senão os conhecimentos priorizados pelas universidades. Para Barros e Paiva (1999), desde os anos 90 a educação aparece como um motor de transformação social e são os professores que devem concretizá-la. É aí que a pesquisa da prática pedagógica torna-se fundamental.

\section{A profissionalização}

Pouco numerosos são os estudos que tratam da profissionalização do corpo docente. Entretanto, partindo das noções de ator, de agente ou de sujeito, alguns trabalhos dedicam-se à análise do percurso pessoal e profissional de professores de $1^{\mathrm{a}}$ a $4^{\mathrm{a}}$ série. Três fatores retêm a atenção desses pesquisadores: o sexo, a profissão e a identidade do professor.

Esses trabalhos assinalam que os professores são tocados por um sentimento paradoxal: de um lado está a profunda desilusão oriunda da incompa- 
tibilidade entre as expectativas produzidas ao longo da formação inicial e os limites impostos pela realidade profissional; de outro, está a esperança de construir uma escola pública de qualidade. Entretanto, esse sentimento está longe de proporcionar um olhar crítico sobre a educação escolar e de encorajar o engajamento nas lutas pela democratização da educação.

Assunção (1995) observa que o sexo é um dos fatores determinantes da escolha da profissão, influenciando as expectativas frente à formação e a prática pedagógica. Esta constatação é corroborada por Assis et al. (1998), para quem o fator sexo é decisivo na constituição da identidade de professor.

Segundo Gemaque (1995), ainda que a profissionalização seja essencial à construção da identidade docente, ela não é objeto de interesse dos professores, nem dos cursos de formação ou dos sindicatos e associações da categoria. Para Ramalho (1996), ${ }^{9}$ esses cursos ignoram os fatores de profissionalização do magistério porque estão baseados em modelos educacionais que privilegiam unicamente os conteúdos escolares. Além disso, os professores que têm os níveis de escolaridade mais baixos estão menos ligados à profissão. O autor refere-se a uma "desprofissionalização" do ensino de $1^{\circ}$ grau, que atinge sobretudo as populações mais desfavorecidas. Isso é resultado de uma formação deficiente, de baixos salários, de condições precárias de trabalho, de ausência de critérios de recrutamento e seleção, de interferência político-partidária na escola, da falta de organização e de autovalorização e do fato de ser uma profissão exercida maciçamente por mulheres.

Segundo Cancian (1998), a prática pedagógica deve ser fruto de uma experiência coletiva ou de um "processo comunicativo", experimentado no interior da escola, pois é nesse processo que o professor constrói sua identidade profissional. Considerando-se que a profissionalização não é um processo acabado, Bastos e Nascimento (1998) observam que ela se realiza de diferentes maneiras e em múltiplos espaços educativos. Porém, as instâncias de escolarização formal devem desempenhar um papel prioritário na profissionalização dos professores, sublinham os autores.

9 Baseando-se em abordagens que tratam da educação contínua, Enricone e Faria (1998) ressaltam o papel da formação na profissionalização dos especialistas em educação. A construção de um projeto pedagógico coletivo depende também destes profissionais, insistem eles. 


\section{A formação dos professores}

A formação inicial e contínua aparece num número significativo de pesquisas. ${ }^{10}$ Quatro temas podem ser destacados: a revisão do currículo, as políticas educacionais, a formação universitária do professor de $1^{\mathrm{a}} \mathrm{a} 4^{\mathrm{a}}$ série e a formação contínua. ${ }^{11}$ Todos mencionaram o engajamento/desengajamento da universidade na melhoria da qualidade da escola pública.

A revisão do currículo aparece como resultado do esforço de alguns professores universitários, interessados na situação da Educação Básica e na redefinição do papel das instituições públicas de ensino superior. São igualmente as noções de professor ator, agente ou sujeito que orientam essas experiências. Os pesquisadores consideram que as faculdades de educação beneficiaram-se das revisões curriculares, pois, aproximando-se dos sistemas de ensino, puderam reavaliar suas concepções filosóficas e reestruturar seus programas de formação.

Para Silva e Guimarães (1998), essas revisões curriculares não se limitam a mudanças nas grades, mas apresentam uma forte conotação política e uma crítica à tendência tecnicista que orientou os programas de formação, desde os anos 70: mais do que reorganizar as habilitações para o ensino, essas experiências encorajavam a transformação da escola e da sociedade, observam os autores.

Analisando os limites da nova Lei de Diretrizes e Bases da Educação Nacional (1996), Brzezinski (1997) afirmam que, apesar das experiências bem sucedidas de várias faculdades de educação, a concepção de formação de professores permanece fragmentada: as medidas previstas por esta Lei desvalorizam o profissional da educação e são um obstáculo à consolidação da identidade de professor. Loureiro, Oliveira e Silva (1999) assinalam que a política educacional do governo tenta retirar da universidade qualquer responsabilidade na formação docente e investe em uma formação acelerada, que não leva em conta a qualidade do ensino.

${ }^{10}$ A respeito das pesquisas sobre a formação de professores no Brasil, ver: André, Simões, Carvalho e Brzezinski (1999). Sobre os processos de formação de professores, ver: Azambuja e Oliveira (2000).

${ }^{11}$ Examinando, desde 1990, os periódicos que tratam da formação contínua, Carvalho e Simões (1999) observam que o professor aparece no centro desta modalidade de formação, sendo concebido como sujeito individual e coletivo da competência profissional. Os conceitos-chave dessas análises referem-se à articulação dos conhecimentos, à experiência prática, à reflexão sobre a ação e à reflexão na ação, à pesquisa da própria prática, à atividade de classe conduzida pela escola e suas relações com o contexto sociohistórico mais geral. 
Da mesma maneira, Silva (1998 e 1999) nota que, para os professores universitários, os programas de formação estão marcados mais pela pressa em diplomar do que pela preocupação com a qualidade. Investir na formação universitária dos professores de $1^{\mathrm{a}}$ a $4^{\mathrm{a}}$ série significa investir em um perfil profissional: trata-se de dotá-los de uma maior autonomia intelectual para pensar, inventar, adaptar as prescrições pedagógicas, ao invés de segui-las quase cegamente.

A experiência de formação inicial dos professores, analisada por Mendes e Silva (1999), é considerada como positiva porque "foi o fruto de um trabalho coletivo". Essa experiência visava a formação de um professor pesquisador, crítico, reflexivo e criativo. A partir de um trabalho interdisciplinar, associando os conhecimentos teóricos aos conteúdos específicos, os cursos propõem-se a fornecer as bases para a compreensão da realidade socioeconômica, política e cultural. Os aspectos positivos da participação dos protagonistas foram ressaltados por Freitas e Villani (1999) no exame de uma outra experiência de formação inicial: os estudantes engajaram-se cada vez mais em sua própria formação profissional, constatam os pesquisadores.

Formação contínua, formação em serviço (GONÇALVES et al., 1999) ou formação permanente são expressões utilizadas como sinônimo na maioria dos trabalhos. Mesmo aqueles que se propõem a conceituá-las não fazem, na verdade, distinção entre uma e outra. Ainda que a maioria dos cursos oferecidos pela administração dos sistemas de ensino ou pela universidade não seja regular, observamos que os trabalhos preferem considerá-los como formação contínua. Essa modalidade de formação foi criticada em diferentes pontos: concepção, falta de transparência política, dinâmica de execução, falta de avaliação das mudanças provocadas, dicotomia entre teoria e prática, falta de continuidade. Porém, sua contribuição nas transformações esperadas foi objeto de interesse de alguns pesquisadores.

Andaló (1995) constata que o governo usou os cursos de capacitação como única solução para resolver o problema do fracasso escolar, ignorando a experiência profissional dos professores: ainda que a prática pedagógica seja reconhecida como resultado da competência profissional construída historicamente, esses cursos tendem a desconsiderar suas aquisições e a dimensão cotidiana do trabalho de classe.

Quanto aos programas de capacitação (postos em prática pela Secretaria da Educação entre 1986 e 1993 em Florianópolis), Silva e Vencato (1998) observam que a política de formação não era claramente explicitada e que os cursos haviam sido impostos aos professores, o que os havia desencorajado consideravelmente. Os conteúdos tratados eram bastante críticos, visando 
desmistificar a noção tradicional de fracasso escolar, refletir sobre a dicotomia entre teoria e prática e convencer os professores a valorizarem os conhecimentos dos alunos. No entanto, os cursos não souberam aproveitar a competência profissional dos docentes, pois os "modismos" predominaram.

Segundo Barros e Paiva (1999), a formação contínua pode contribuir para romper com o isolamento em que se encontram os professores de $1^{\mathrm{a}} \mathrm{a} 4^{\mathrm{a}}$ série. Entretanto, esses cursos limitam-se a transmitir conteúdos, técnicas e métodos de ensino, sem valorizar a bagagem trazida pelos professores: eles são orientados quanto ao por quê fazer, o quê fazer, como fazer, julgados adequados por experts externos à escola. $\mathrm{O}$ que pode explicar o sentimento de desconfiança e as resistências dos professores diante dos cursos, supõem os autores.

Brunstein et al. (1996) observam que os programas de formação em serviço (aplicados em todas as regiões pelo Ministério da Educação) não foram seguidos de uma avaliação que permitisse medir seu impacto sobre a aprendizagem dos alunos. É preciso recomeçar tudo por ocasião da aplicação de um outro programa, uma vez que esses não se prestaram ao feedback.

Participando de um programa de pesquisa/intervenção, Del Prette e Del Prette (1997) encontraram, entre os professores, uma grande preocupação quanto à sua competência profissional, pois desejando mudar sua prática pedagógica, os professores depositaram muita esperança nessa experiência, acreditando que a interação entre colegas seria útil.

Para Santos e Morais (1998), a evolução científica recente não foi suficientemente valorizada pelos cursos de capacitação, pois eles não fornecem referências suficientes aos professores para melhor selecionar os conteúdos e métodos pedagógicos. Além disso, esses cursos não criam espaço de reflexão sobre a prática pedagógica, nem oportunidades de trocas com seus pares.

Segundo Sordi e Camargo (1998), a universidade deve inserir-se no processo de "requalificação dos professores". Para tal, é preciso ultrapassar a dicotomia entre teoria e prática, entre o mundo acadêmico e a experiência cotidiana da escola pública. Para Foerste (1998) ${ }^{12}$ a socialização profissional começa na formação inicial e se concretiza ao longo da formação contínua. Logo, os programas de formação podem aproximar a universidade da Escola Básica e favorecer sua integração.

12 Analisando o conteúdo dos periódicos nacionais sobre a educação, este pesquisador constata que eles privilegiam a política, a democratização, o planejamento e a gestão educativa, o ensino médio, o financiamento da educação, a participação comunitária na vida escolar, o papel do professor, e seu percurso profissional. 
Os pesquisadores observam que os professores sentem-se profundamente aborrecidos pela falta de continuidade dos cursos. Segundo Silva e Schnetzler (1998), os programas de formação das universidades seguem a mesma sistemática utilizada pelas secretarias de educação: são cursos pequenos que apresentam algumas receitas e fazem parte dos pacotes de reciclagem, não levando em conta a prática pedagógica dos professores.

Analisando as representações de professores sobre os cursos de formação, Sobreira (1996) observa que aqueles que valorizaram a experiência dos professores e permitem seu envolvimento na programação foram avaliados positivamente. Catapan (1998) constata, a partir do estudo de experiências inovadoras de gestão e de formação em Santa Catarina, que os professores mostram-se satisfeitos quando podem trocar sua base de conhecimentos e aprofundar suas experiências. Esta constatação se opõe aos que questionam o interesse dos professores pelos programas de capacitação.

O exame dos trabalhos possibilitou uma nova visão, ao mesmo tempo global e atualizada, do campo educacional brasileiro. Pudemos observar, para concluir, que:

1. A pesquisa em educação, no Brasil, não é somente efeito do acaso, de uma escolha pessoal mais ou menos ditada pelos imprevistos e desafios da função universitária. A pesquisa abre hoje novas perspectivas e dá sentido à atividade do magistério (em todos os níveis). Por esta razão, uma nova era se anuncia, por meio de uma produção intensa de conhecimentos no campo socioeducativo. A diversidade dos trabalhos examinados e a determinação dos pesquisadores interessados são a prova disso;

2. A educação está associada à transformação social e política da sociedade. Para que ela possa tornar-se o motor do desenvolvimento e preparar os cidadãos para enfrentar os desafios do novo milênio, é preciso vencer o desinteresse do Estado na melhoria da educação pública do país, modificando a prática de ensino e os programas de formação do corpo docente. É necessário também reestruturar as relações no interior da escola e as relações desta com as demais instâncias de administração da educação, promovendo a democratização em todos os níveis e redes de ensino. Todos os trabalhos examinados mencionam essa vontade de contribuir para a mudança;

3. O professor (ator, agente ou sujeito) aparece no centro das expectativas relativas à educação pública. Desconfiando das instituições formadoras, os pesquisadores destacam a experiência em sala de 
aula e valorizam o tempo de serviço no magistério. Eles querem com isso que o professor seja capaz de conduzir sua própria socialização profissional, associando a reflexão e a pesquisa ao cotidiano escolar;

4. O engajamento da Universidade na educação pública pode favorecer as transformações pretendidas. O caráter acadêmico do ensino superior é muito criticado, porém essa instituição ocupa um lugar estratégico privilegiado, que deve favorecer os programas de formação inicial e contínua, na socialização profissional do corpo docente da Educação Básica.

Enfim, pudemos observar que a formação dos professores aparece como a pedra fundamental do novo projeto de educação nacional, preconizado pela Lei de Diretrizes e Bases (1996). Esta Lei conferiu-lhe um significado que se mostrou em sintonia com os movimentos dos anos de 1980, que elegeram as dificuldades em termos de formação docente como um dos principais obstáculos à melhoria da educação pública.

Assiste-se assim a uma tendência em deslocar algumas responsabilidades em termos de formação, conferidas antes às universidades, para as novas instâncias educacionais (os institutos superiores de educação), os quais devem igualmente criar suas próprias políticas de formação. Podemos portanto nos questionar, apoiando-nos na análise de Beillerot (1998), ${ }^{13}$ o que está em jogo: a instituição de uma política de educação nacional ou políticas de educação múltiplas, conduzidas pelos diferentes sistemas (público e privado), pelas diversas redes de ensino (federal, estadual e municipal) ou até mesmo pelas próprias instâncias de formação, para uma clientela socialmente distinta portadora de demandas diversificadas?

Para Mello (1999), será preciso estabelecer uma política nacional de formação, estruturada em um consenso construído pelo conjunto dos setores educacionais interessados. O primeiro passo consiste em estabelecer um acordo sobre o caráter nacional da formação dos professores, que é do interesse da nação, pois desta formação depende a produção e a reprodução do processo educacional. A formação aparece como estratégia para a unidade nacional, o pleno exercício da cidadania, a integração e a inclusão social, a sobrevivência em uma economia mundial competitiva. Somente uma forte coesão em torno

${ }^{13} \mathrm{O}$ autor considera que as políticas de educação na França são múltiplas: constata-se a existência de subconjuntos, de instâncias que têm por missão, elas também, conduzir políticas que lhe são próprias (BEILLEROT, 1998). 
da natureza da formação político-pedagógica, tomada como interesse nacional, poderá dar uma total eficiência às diretrizes, aos referenciais ou às recomendações sobre o currículo e sobre a organização pedagógico-institucional dos cursos de formação. Eis aí o conteúdo da política de formação dos professores que está em vias de implantação no Brasil e que se apresenta como um grande desafio à pesquisa educacional.

\section{REFERÊNCIAS}

ALMEIDA, A. Educação e estratificação social: a aprendizagem da diferença. Caxambu: Anped, 2000.

ANDALÓ, C. S. A. O aperfeiçoamento dos professores - uma solução para o fracasso da escola pública? Caxambu: Anped, 1995.

ANDRÉ, M. et al. Estado da arte da formação de professores no Brasil. Educação e Sociedade, Cedes, n. 68, p. 301-309, 1999. Especial.

ANDRÉ, M. E. D. A. O tema da formação docente nas teses e dissertações brasileiras. Caxambu: Anped, 1998.

ANSART, P. Heuristique. Dictionnaire de Sociologie. Paris: Seuil, 1999. p. 255.

ASSIS, G. O. et al. Lembranças de professoras catarinenses. Florianópolis: Anped, 1998.

ASSUNÇÃO, M. M. S. As determinações de gênero na escolha, formação e prática docente das professoras primárias. Caxambu: Anped, 1995.

AZAMBUJA, G.; OLIVEIRA, V. F. Processos de formação de um professor. Caxambu: Anped, 2000.

BACHELARD, G. La formation de l'esprit scientifique; contribution à une psychanalise de la connaissance objective. Paris: Librairie Philosophique J. Vrin, 1965.

BARROS, F. M.; PAIVA, E. V. Propostas para a formação continuada de professores da Secretaria de Estado de Educação do Rio de Janeiro no periodo de 1990 a 1998. Caxambu: Anped, 1999.

BASTOS, F. P.; NASCIMENTO, C. R. Fortalecimento e esclarecimentos do professor: a vivência de um programa de investigação-ação educacional emancipatória no curso normal da rede pública. Florianópolis: Anped, 1998. 
BEILLEROT, J. Les politiques d'éducation. In: RUANO-BORBALAN, J.-J. Éduquer et former. Auxerre: Sciences Humaines, 1998. p. 507-510.

BERGIN, A. Nuevas regulationes del trabajo docent; l'analyse de la réforme éducationnelle de l'Argentine. Caxambu: Anped, 1998.

BRUNSTEIN, R. L. et al. Reformulação dos cursos de formação de professores na $U F G$ : concepções, propostas e campos científicos em disputa. Caxambu: Anped, 1995.

. Formação continuada de professores do ensino: análise de programas selecionados nas cinco regiões do país. Caxambu: Anped, 1996.

BRZEZINSKI, I. Perplexidades na formação de profissionais da educação frente a LDB 9.394/96: ressignificação da formação do pedagogo. Caxambu: Anped, 1997.

BUENO, B.O. O método autobiográfico e os estudos com histórias de vida de professores: a subjetividade e a questão das representações. Caxambu: Anped, 1997.

CANCIAN, V. A. Processo de aprendizagem do professor à luz da racionalidade comunicativa. Florianópolis: Anped, 1998.

CARVALHO, J. M.; SIMÕES, R. H. S. Formação continuada do professor por meio da pesquisa de sua prática. Caxambu: Anped, 1996.

. O que dizem os artigos publicados em periódicos especializados, na década $\overline{\text { de }} 90$ sobre o processo de formação continuada do professor? Caxambu: Anped, 1999.

CATAPAN, A. H. Experiências inovadoras/exitosas de gestão da educação em Santa Catarina. Florianópolis: Anped, 1998.

CORD, D. Fracasso escolar: as origens do discurso. Florianópolis: Anped, 1998.

DAROS, M. D. et al. A sociologia na formação dos professores catarinenses. Caxambu: Anped, 2000.

DEL PRETTE, Z. A. P.; DEL PRETTE, A. Um programa de desenvolvimento de habilidades sociais na formação continuada do professor. Caxambu: Anped, 1997.

DICKEL, A. Aliando pesquisa, práxis et produção coletiva: a trajetória de um grupo de professoras-pesquisadoras na luta pela reapropriação do trabalho docente. Caxambu: Anped, 1997.

. Buscando referências para a discussão sobre a formação do professor-pesquisador - contribuições para o debate. Caxambu: Anped, 1998.

ENGERS, M. E. A. Repercussões da cultura no cotidiano escolar das séries iniciais: implicações na educação de professores. Florianópolis: Anped, 1998.

ENRICONE, D. C.; FARIA, E. T. Formação pedagógica de especialistas da educação: uma proposta de estudos continuados. Florianópolis: Anped, 1998. 
FERREIRA, R. A. A sociologia da educação no Nordeste: a trajetória de uma disciplina. Caxambu: Anped, 1999.

FOERSTE, E. Abordagens sobre integração universidade e escola básica: uma discussão a partir de periódicos nacionais de educação. Caxambu: Anped, 1998.

FORQUIN, J.-C. L'usage des synthèses dans la recherche en éducation. Communication documentaire; perspectives documentaires en éducation, n. 37, p. 71-79, 1996.

FREITAS, D.; VILLANI, A. Análise e interpretação de uma experiência de formação inicial de professores. Caxambu: Anped, 1999.

GEMAQUE, R. O magistério como profissão na visão de professores de $1^{\circ}$ e $3^{\circ}$ graus. Caxambu: Anped, 1995.

GONÇALVES, M. A. S.; DIAS, A. R. G.; FONSECA, M. R. Formação do professor em serviço: uma experiência de pesquisa-ação com professoras das classes empobrecidas. Caxambu: Anped, 1999.

GRILLO, M. et al. Transposição didática: uma prática reflexiva. Caxambu: Anped, 1998.

LINHARES, C. F. Formação de professores no Brasil: entre o discurso acadêmicopedagógico e a escola pública fundamental. Caxambu: Anped, 1995.

LOUREIRO, W. N.; OLIVEIRA, J. F; SILVA, A. F. A formação e profissionalização docente. Caxambu: Anped, 1999.

MAZZA, D. A produção sociológica de Florestan Fernandes e suas interfaces com a sociologia da educação. Caxambu: Anped, 1999.

MELLO, G. N. Formação inicial de professores para a educação básica: uma revisão radical; documento principal (versão preliminar para discussão interna). São Paulo: MEC, out./nov. 1999.

MELLO, R. R. Formação básica, formação continuada e percurso profissional, sob a perspectiva de quatro professoras. Caxambu: Anped, 1998.

MENDES, O. M.; SILVA, R. V. S. Os objetivos dos cursos de licenciatura da UFU para formar professores. Caxambu: Anped, 1999.

NUÑEZ, I. B.; RAMALHO, B. L. Um modelo profissional: uma necessidade para a formação do profissional? Caxambu: Anped, 1997.

PEREIRA, G. R. M.; CATANI, D. B.; CATANI, A. M. As apropriações da obra de Pierre Bourdieu no campo educacional brasileiro. Caxambu: Anped, 2000.

RAMALHO, B. L. A formação como base da profissionalização docente. Caxambu: Anped, 1996. 
SANTOS, C. F.; MORAIS, A. G. O ensino de língua portuguesa e a formação em serviço do professor das séries iniciais: um estudo de caso numa rede pública estadual. Caxambu: Anped, 1998.

SILVA, A. F.; GUIMARÃES, M. T. C. Reformulação dos cursos de formação de professores na UFG: concepções, propostas e campos científicos em disputa. Caxambu: Anped, 1998.

SILVA, L. H. A.; SCHNETZLER, R. P. Buscando o caminho do meio: construindo a parceria entre professores e formadores de professores de ciências. Caxambu: Anped, 1998.

SILVA, V. L. G.; VENCATO, A. P. Aperfeiçoamento docente... para quem? Florianópolis: Anped, 1998.

SILVA, W. C. A universitarização da formação do professor das séries iniciais do ensino fundamental: análise sociológica da experiência desenvolvida na UERJ. Caxambu: Anped, 1998.

. A criação dos institutos superiores de educação no Brasil: alternativa superior para a formação de professores. Caxambu: Anped, 1999.

SOBREIRA, H. Formação de professores: dois tópicos de uma elaboração alternativa. Caxambu: Anped, 1996.

SORDI, M. R. L; CAMARGO, A. L. C. A formação do professor e o papel da universidade: competência aliada à produção. Caxambu: Anped, 1998.

SPILIMBERG, F. B.; OLIVEIRA, V. D. A reflexão sobre a prática docente como recurso à formação continuada. Florianópolis: Anped, 1998.

TORNQUIST, C. S.; VALLE, I. R. A sociologia no ensino de $2^{\circ}$ grau: entre o cimento armado e a terra fértil. Leituras e Imagens, Florianópolis: Udesc, p. 11-20, 1995.

VALLE, I. R. Professionnalisation et formation des enseignants: la socialisation professionnelle des enseignants de la $1^{\mathrm{er}}$ à la $4^{\mathrm{e}}$ année à Santa Catarina - Brésil. Paris, 2001. Thèse (Doctorat) - Paris V.

VILELA, R. A. T. Estar professora - ser professora: identidade profissional de professores primários. Caxambu: Anped, 2000.

ZAGO, N. Percursos escolares no primeiro grau: significados e práticas familiares de escolarização. Florianópolis: Anped, 1998.

ZASSO, S. M. B. Em busca de caminhos teóricos metodológicos para a formação de um pedagogo reflexivo. Caxambu: Anped, 1998.

Texto recebido em 23 ago. 2004

Texto aprovado em 15 set. 2004 